\title{
O ENVOLVIMENTO DO SISTEMA COMPLEMENTO NOS PROCESSOS DE ATEROGÊNESE
}

\author{
THE INVOLVEMENT OF THE COMPLEMENT SYSTEM IN THE PROCESSES IN ATHEROGENESIS
}

Ana Paula Landi Librandi ${ }^{1}$, Ana Isabel de Assis Pandochi ${ }^{2}$

${ }^{1}$ Doutora em Ciências Farmacêuticas, ${ }^{2}$ Docente. Departamento de Física e Química, Faculdade de Ciências Farmacêuticas de Ribeirão Preto, USP.

Correspondência: Ana Paula Landi Librandi. Universidade de São Paulo, Faculdade de Ciências Farmacêuticas de Ribeirão Preto, Departamento de Física e Química. Av. do Café s/n. Ribeirão Preto, SP, Brasil. 14040-903. Tel: +55 1636024212 / Fax: +55 16 36332960. (E-mail address: aplandi@lycos.com)

Landi-Librandi AP, Assis-Pandochi Al. O envolvimento do sistema complemento nos processos de aterogênese. Medicina (Ribeirão Preto) 2008; 41 (3): 312-26.

RESUMO:A aterosclerose é considerada como uma doença inflamatória crônica desencadeada pela ativação de macrófagos, linfócitos T e sistema complemento (SC). O SC corresponde a um grupo de proteínas plasmáticas e de membrana, as quais são ativadas por uma cascata de interações que resultam na produção de várias moléculas pro-inflamatórias. Embora seja um dos mecanismos efetores do sistema imune inato, em certas circunstâncias, o SC pode por si contribuir para o desencadeamento de doenças cardiovasculares. Esta revisão contêm uma descrição sumarizada da cascata do SC e dos processos de aterogênese bem como o envolvimento de fatores imunológicos, em especial o SC, na patogênese da aterosclerose.

Palavras-chave: Proteínas do Sistema de Complemento. Aterosclerose. Inflamação. Complexo de Ataque à Membrana de Complemento. Aterogênese.

\section{1- INTRODUÇÃ̃O}

A aterosclerose humana é uma doença inflamatória multifatorial na qual a formação da placa aterosclerótica parece ser a via final comum para vários mecanismos etiopatogênicos. Estas lesões consistem comumente de um agregado de células espumosas derivadas inicialmente de monócitos-macrófagos, e musculares lisas que migraram para a camada íntima do vaso ou de placas fibrosas constituídas da proliferação de células musculares lisas e matriz extracelular hiperplásica e se localizam principalmente em artérias musculares e elásticas de médio e grande calibre. Cada uma destas duas formas histopatológicas também contém linfócitos $\mathrm{T}$ e diferentes quantidades de depósitos de lipídeos extracelulares. Dentre os mecanismos etiopatogênicos, fatores cha- ve até então identificados mas não completamente compreendidos são a susceptibilidade genética individual, estresse hemodinâmico e a combinação de vários fatores de risco como hipercoloesterolemia, diabetes, hipertensão, tabagismo, inflamação, infecção viral, e outros. A aterosclerose e suas principais complicações, infarto cerebral e do miocárdio, constituem uma das maiores causas atuais de morte no mundo. $\mathrm{O}$ Sistema Complemento (SC) está envolvido em várias formas de doenças cardiovasculares. A ativação deste sistema exacerba o dano do miocárdio seguido de isquemia ${ }^{1}$; está envolvida na vasculite por imunocomplexos (IC) ${ }^{2}$ e também contribui para aterosclerose em órgãos transplantados ${ }^{3,4}$. Vários estudos revelam a participação de mecanismos da resposta imune humoral na aterogênese ${ }^{5 / 9}$. Dentre eles, a ativação do $\mathrm{SC}$ tem sido associada com estágios prelesionais bem 
como com a progressão da lesão aterosclerótica. Existem ainda evidências do envolvimento do SC na geração espontânea de lesões ateroscleróticas ${ }^{10}$, podendo ser um fator iniciador na formação da lesão ${ }^{11}$.

Esta revisão contém uma descrição sumarizada da cascata do SC e sua regulação, e da aterosclerose com enfoque na sua característica de doença inflamatória crônica, sustentando o envolvimento de fatores imunológicos na patogênese desta doença. Finalmente, sumariza evidências da participação do SC no processo que inicia a formação da lesão aterosclerótica, considerando principalmente os mecanismos pelos quais este sistema pode ser ativado na parede arterial e os potenciais efeitos de seus componentes nas células arteriais.

\section{2- SISTEMA COMPLEMENTO (SC)}

O complemento corresponde a um ramo central da imunidade inata comprendendo um sistema de mais de 30 proteínas plasmáticas e de membrana, sendo um mediador importante do processo inflamatório, e podendo atuar independentemente ou em colaboração com outros mecanismos de defesa da imunidade inata e adquirida do hospedeiro. Em termos de concentração, compreende mais de $3 \mathrm{~g}$ de proteína por litro de plasma (Tabela I). A participação na fagocitose favorecendo a opsonização, a quimiotaxia e ativação de leucócitos; a inibição da formação de precipitado de IC e a solubilização dos IC pré-formados; a remoção de IC; a lise celular e a participação na resposta imune são atividades importantes do SC.

Dependendo do estímulo, a ativação do SC ocorre por três vias distintas, denominadas vias clássica (VC), alternativa (VA), e via da lectina ligante de manose (VL), que convergem para a formação de complexos enzimáticos denominados " $\mathrm{C} 3$ convertases" e "C5 convertases". Fragmentos dos componentes, bem como complexos macromoleculares sem atividade enzimática, resultantes desta ativação ${ }^{13}$, são mediadores das funções biológicas do complemento. As reações subsequentes à ativação de C5 são comuns às três vias e terminam com formação do "complexo de ataque à membrana" (MAC) ${ }^{14}$ (Figura 1).

Tabela I. Componentes do Sistema Complemento: proteínas plasmáticas envolvidas na ativação.

\begin{tabular}{lll}
\hline Componente & $\begin{array}{l}\text { Peso Molecular em kD } \\
\text { da proteína intacta }\end{array}$ & $\begin{array}{l}\text { Concentração plasmá- } \\
\text { tica }(\mu \mathrm{g} / \mathrm{mL}\end{array}$ \\
\hline $\begin{array}{ll}\text { Comum a todas vias de ativação } \\
\text { C3 }\end{array}$ & $185(\alpha, 110 ; \beta, 75)$ & $1.200-1.300$ \\
\hline Via Alternativa & 93 & 200 \\
Fator B & 24 & 2 \\
Fator D & $110,165,200$ (monômero:55) & 25 \\
Properdina (predominância de oligômeros) & & \\
Via Clássica & 460 & 150 \\
C1q & 85 & 50 \\
Clr & 85 & 50 \\
C1s & $205(\alpha, 97 ; \beta, 75 ; \gamma, 33)$ & $300-600$ \\
C4 & 102 & 20 \\
C2 & & $1(0,01-20)$ \\
Via da Lectina & $200,300,400$ & $1,5-12$ \\
MBL (formas predominantes) & 100 & nd \\
MASP-1 & 76 & 80 \\
MASP-2 & & 45 \\
\hline Via Terminal & $190(\alpha, 115 ; \beta, 75)$ & 90 \\
C5 & 110 & 55 \\
C6 & 100 & 60 \\
C7 & $150(\alpha, 64 ; \beta, 64 ; \gamma, 22)$ & \\
C8 & 70 & \\
C9 &
\end{tabular}

MBL, lectina ligante de manana; MASP, serina-protease associada a MBL; nd, não determinado. Adaptado de Paul, $1999{ }^{12}$. 


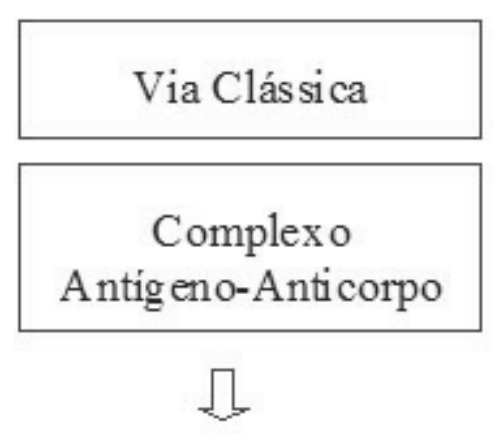

$\mathrm{C} 1, \mathrm{C} 4, \mathrm{C} 2$
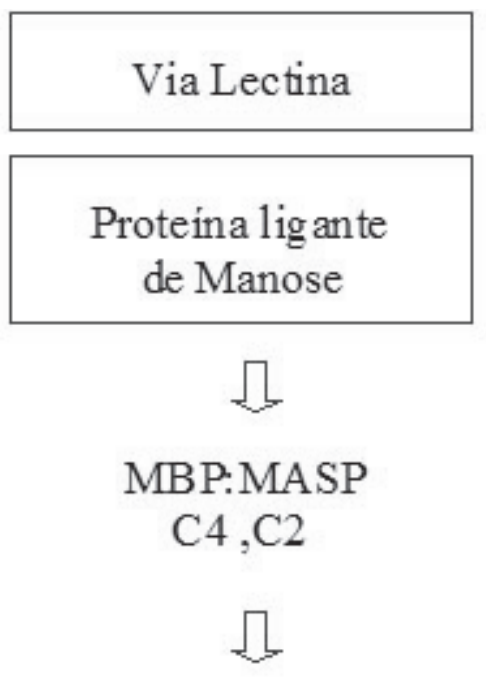

C3 convertase

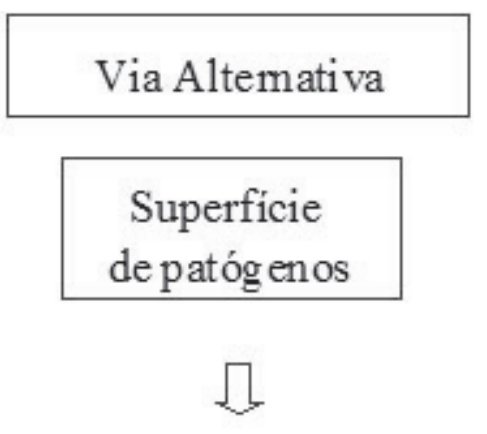

C3, B, D

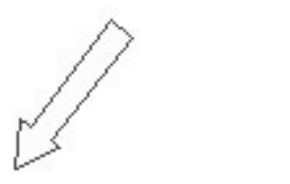<smiles>[Te]</smiles>

$\mathrm{C} 3 \mathrm{~b} \Rightarrow \mathrm{C} 5 \mathrm{~b}, \mathrm{C} 6, \mathrm{C} 7, \mathrm{C} 8, \mathrm{C} 9$

C5 convertase

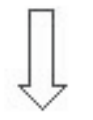

MAC

Lise de células e patógenos

Figura 1. Esquema representando as três vias de ativação do sistema Complemento. Adaptado de Paul, $1999{ }^{12}$.

\section{1- Mecanismos de ativação do SC}

\subsection{1- Ativação da Via clássica}

É iniciada majoritariamente pela ligação de $\mathrm{C} 1$

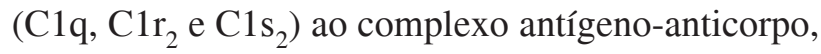
embora outras moléculas possam ativar $\mathrm{C} 1$, como por exemplo, proteínas $\mathrm{C}$ reativa (PCR) e amilóide sérica $\mathrm{P}$ (PAS), as quais podem se ligar a constituintes nucleares liberados por células danificadas bem como a superfícies de várias bactérias e vírus ${ }^{15}$, por membrana endotelial e de células apoptóticas ${ }^{16,17}$. C1s cliva $\mathrm{C} 4$ em C4a e $\mathrm{C} 4 \mathrm{~b}$ expondo um grupo tioéster interno, inacessível no $\mathrm{C} 4$ nativo, que possibilita a ligação covalente a grupos amina e hidroxila de superfícies (superfície bacteriana, células, proteínas ou glicoproteínas, etc) ${ }^{18}$. C2 se associa a C4b e é clivado por $\mathrm{C} 1 \mathrm{~s}$ em $\mathrm{C} 2 \mathrm{a}$ e $\mathrm{C} 2 \mathrm{~b}$, o qual permanece ligado a
$\mathrm{C} 4 \mathrm{~b}$ formando a C3 convertase da $\mathrm{VC}(\mathrm{C} 4 \mathrm{~b} 2 \mathrm{~b})$. Este complexo enzimático atua sobre $\mathrm{C} 3$ clivando-o em dois fragmentos, C3a e C3b. Similar ao C4b, C3b também expõe um grupo tioéster interno, inacessível no C3 nativo, que possibilita sua ligação covalente a grupos amina e hidroxila ${ }^{18}$. C3b depositado interage com $\mathrm{C} 4 \mathrm{~b} 2 \mathrm{~b}$ formando a $\mathrm{C} 5$ convertase desta via (C4b2b3b), que cliva C5 em C5a e C5b dando início à ativação da via terminal do SC.

\subsubsection{Ativação da Via das Lectinas}

É desencadeada pela ligação do complexo proteína ligante de manose (MBL)- serino proteases (MASP1, 2 e 3) a sequências de resíduos repetidos de manose presentes na superfície do patógeno. Esta ligação provavelmente resulta em mudanças conformacionais e consequente ativação das MASPs, com 
clivagem de $\mathrm{C} 4$ e $\mathrm{C} 2$ e formação de $\mathrm{C} 4 \mathrm{~b} 2 \mathrm{~b}$. Os passos seguintes de ativação são os mesmos da $\mathrm{VC}^{19}$. Também são ativadores desta via ficolina $\mathrm{H}$ e P35 $5^{20}$ bem como complexos imunes de $\operatorname{Ig} \mathrm{A}^{21}$. Esta via é particularmente importante no reconhecimento e remoção de patógenos, estando a deficiência de seus componentes fortemente associada a infecções recorrentes ${ }^{22}$.

\subsection{3-Ativação da Via Alternativa}

A ativação desta via independe da presença de complexos antígeno-anticorpo. Pode ser desencadeada por vários ativadores, tais como fungos ${ }^{23}$, lipopolissacarídeos $^{24}$, eritrócitos de coelho ${ }^{25}$. Pode ser iniciada de forma independente das VC e VL, pela ligação covalente de pequenas quantidades de $\mathrm{C} 3 \mathrm{~b}$ a grupos hidroxila de carboidratos da superfície ativadora. Esta pequena quantidade de $\mathrm{C} 3 \mathrm{~b}$ é constantemente originada pela clivagem de $\mathrm{C} 3$ no plasma por proteases séricas ou pela $\mathrm{C} 3\left(\mathrm{H}_{2} \mathrm{O}\right) \mathrm{Bb}$, denominada "C3 convertase de fase fluida" da VA, que tem vida média bastante curta. Esta enzima é formada pela ação de nucleófilos como a água, gerando moléculas $\mathrm{C} 3\left(\mathrm{H}_{2} \mathrm{O}\right)$ ou C3 "C3b-like", com propriedades conformacionais semelhantes ao $\mathrm{C} 3 \mathrm{~b}^{26}$. Este $\mathrm{C} 3\left(\mathrm{H}_{2} \mathrm{O}\right)$ liga-se ao fator $\mathrm{B}$ formando $\mathrm{C} 3\left(\mathrm{H}_{2} \mathrm{O}\right) \mathrm{B}$. O fator D então cliva o fator $\mathrm{B}$, formando $\mathrm{C} 3\left(\mathrm{H}_{2} \mathrm{O}\right) \mathrm{Bb}$. Na ausência de uma "superfície ativadora", as moléculas de $\mathrm{C} 3 \mathrm{~b}$ geradas por esta $\mathrm{C} 3$ convertase de fase fluida ligam-se a cofatores do fator I e são rapidamente inativadas por esta enzima plasmática, interrompendo o processo de ativação do SC neste estágio. Tendo se ligado a uma "superfície ativadora", o C3b combina-se preferencialmente com fator B (na presença de íons magnésio), possibilitando a clivagem deste pelo fator $\mathrm{D}$ e gerando os fragmentos $\mathrm{Ba}$ e $\mathrm{Bb}$. $\mathrm{Bb}$ permanece associado a $\mathrm{C} 3 \mathrm{~b}$ formando $\mathrm{C} 3 \mathrm{bBb}$, a $\mathrm{C} 3$ convertase de membrana da VA. A clivagem de novas moléculas de $\mathrm{C} 3$ gera novos fragmentos $\mathrm{C} 3 \mathrm{~b}$, que se unem à $\mathrm{C} 3$ convertase, formando $\mathrm{C} 3 \mathrm{bBb} 3 \mathrm{~b}, \mathrm{a} \mathrm{C} 5$ convertase desta via.

\subsection{4- Ativação da via terminal do complemen- to, formação do complexo de ataque à membrana (MAC)}

Os últimos componentes do SC ligam-se sequencialmente uns aos outros, gerando o Complexo de Ataque à Membrana (MAC). A formação do MAC é iniciada quando $\mathrm{C} 5 \mathrm{~b}$ gerado pela $\mathrm{C} 5$ convertase ligase a C6 e forma um complexo de fase fluida C5b6. A ligação de $\mathrm{C} 7$ gera no complexo um sítio hidrofóbico metaestável que o torna capaz de se inserir em mem- branas. A inserção mais efetiva ocorre no próximo passo, onde C8 se liga a C5b-7, formando C5b-8. C5b-8 inserido na membrana constitui um receptor para múltiplas moléculas de C9. A ligação e polimerização de várias moléculas de $\mathrm{C} 9$ forma um canal na membrana ou "leaky patches"27, levando à perda do equilíbrio hidroeletrolítico, com consequente indução de lise da célula alvo. Células nucleadas são mais resistentes podendo se defender da lise mediada pelo MAC, ocorrendo então os "efeitos não letais do MAC" ${ }^{28}$, como por exemplo ativação de funções celulares importantes.

\subsection{5- Funções biológicas decorrentes da ativa- ção do SC}

A ativação do complemento libera as anafilatoxinas C3a e C5a envolvidas nos processos inflamatórios agudos causando atração e ativação de células ${ }^{29}$. Estes peptídeos ligam-se a receptores específicos presentes na superfície de vários tipos celulares, desencadeando respostas como vasodilatação, desgranulação de mastócitos, aumento da permeabilidade vascular e migração celular (C5a), ativação e atração de leucócitos do sangue para tecidos alvos (C5a), etc. Por outro lado, o SC também pode desempenhar atividade antiinflamatória pela promoção da remoção de IC da circulação e de tecidos ${ }^{30}$ através de receptores específicos, evitando a deposição e desencadeamento ou exacerbação de processos inflamatórios ${ }^{31}$. Assim, IC opsonizados por iC3b ligam-se ao receptor CR1 em hemácias e são então transportados pela circulação até o sistema fagocítico mononuclear do fígado e baço, onde são transferidos para os macrófagos através dos receptores para Fc destas células ${ }^{32,33}$. Os fragmentos C4b e C3b são considerados importantes opsoninas e são reconhecidos por receptores específicos (CR1 e CR3) na superfície de células fagocíticas tais como leucócitos polimorfonucleares e monócitos, tornando o processo da fagocitose mais eficiente ${ }^{34}$.

A atividade citolítica foi a primeira função reconhecida do SC. No entanto como citado anteriormente, células nucleadas podem reparar o dano causado pela deposição do MAC; em doses sublíticas este complexo pode promover os chamados "efeitos não letais do MAC", estimulando ou inibindo funções celulares importantes, como por exemplo, ação indireta na inflamação devido a liberação de ácido araquidônico e síntese de mediadores como leucotrienos, tromboxanas e prostaglandinas, exocitose/endocitose devido ao aumento do cálcio intracelular e produção de metabólitos de oxigênio reativo $\left(\mathrm{O}_{2}-, \mathrm{H}_{2} \mathrm{O}_{2}, \mathrm{OH}\right.$.), regeneração de tecidos, $\operatorname{etc}^{28,35}$. 


\subsection{6-Regulação do SC}

Devido à sua tendência de rápida ativação e à capacidade de amplificar este processo, o SC necessita ser bem controlado, evitando ativação em locais e/ou momentos inadequados ou até mesmo descontrolada e depleção consequente de suas proteínas, com geração de excesso de fragmentos proteícos e/ou complexos ativos que teriam efeitos lesivos para o organismo, contribuindo assim para processos patológicos. Este controle ocorre através de vários mecanismos regulatórios que envolvem proteínas solúveis e de membrana (Tabela II). A ação destas proteínas regulatórias ocorre de diversas maneiras e em várias

Tabela II. Proteínas Reguladoras do Complemento.

\begin{tabular}{|c|c|c|c|}
\hline Componente & $\begin{array}{l}\text { Peso Molecular em } \mathrm{kD} \\
\text { da proteína intacta }\end{array}$ & $\begin{array}{l}\text { Concentração plasmática } \\
(\mu \mathrm{g} / \mathrm{mL})\end{array}$ & Ação reguladora \\
\hline \multicolumn{4}{|l|}{ No plasma } \\
\hline Fator I & 88 & 35 & $\begin{array}{l}\text { Responsável pela conversão } \\
\text { de C3b em iC } 3 \text { b }\end{array}$ \\
\hline Fator $\mathrm{H}$ & 150 & $300-450$ & $\begin{array}{l}\text { Regulador da } \mathrm{C} 3 \text { convertase } \\
\text { da via alternativa }(\mathrm{C} 3 \mathrm{bBb}) \text {; } \\
\text { cofator para fator } \mathrm{I}\end{array}$ \\
\hline C1-INH & 105 & 240 & $\begin{array}{l}\text { Inibe as serino-proteases } \mathrm{C} 1 \mathrm{r} \\
\text { e } \mathrm{C} 1 \mathrm{~s} \text { e as MASPs. }\end{array}$ \\
\hline C4bp & $550(7 \times 70,1 \times 45)$ & 250 & $\begin{array}{l}\text { Acelera o decaimento da C3 } \\
\text { convertase da via clássica } \\
\text { (C2a4b) }\end{array}$ \\
\hline Proteína S (Vitronectina) & 84 & 500 & $\begin{array}{l}\text { Liga-se a complexos interme- } \\
\text { diários terminais do comple- } \\
\text { mento, prevenindo a monta- } \\
\text { gem do MAC citolítico na } \\
\text { membrana celular. }\end{array}$ \\
\hline Clusterina (SP-40,40) & $70(35+35)$ & 50 & $\begin{array}{l}\text { Previne inserção de MAC na } \\
\text { membrana celular }\end{array}$ \\
\hline Carboxipeptidase $\mathrm{N}$ & $280(2 \times 90,2 \times 50)$ & 35 & Inativador de anafilatoxinas \\
\hline \multicolumn{2}{|c|}{ Nas membranas celulares } & Distribuição tecidual & \\
\hline CR1 (CD35) & 190 & $\begin{array}{l}\text { Monócitos, macrófagos, } \\
\text { neutrófilos, eosinófilos, } \\
\text { eritrócitos, células T e B }\end{array}$ & $\begin{array}{l}\text { Acelera o decaimento das C3 } \\
\text { e C5 convertases das vias } \\
\text { clássica e alternativa. Atua } \\
\text { como cofator para fator I. }\end{array}$ \\
\hline DAF (CD55) & 70 & $\begin{array}{l}\text { Células sanguíneas peri- } \\
\text { féricas (exceto: NK), eritró- } \\
\text { citos, células secretoras e } \\
\text { epiteliais, células endo- } \\
\text { teliais }\end{array}$ & $\begin{array}{l}\text { Dissocia ou previne a } \\
\text { formação das convertase } \\
\text { (C3 e C5 convertases) das } \\
\text { vias clássica e alternativa }\end{array}$ \\
\hline $\mathrm{MCP}(\mathrm{CD} 46)$ & $\begin{array}{l}\text { 45-70 } \\
\text { (devido glicosilação) }\end{array}$ & $\begin{array}{l}\text { Igual a DAF (exceto: } \\
\text { eritrócitos) }\end{array}$ & $\begin{array}{l}\text { Atua como cofator para ofa- } \\
\text { tor I na clivagem de C } 3 \mathrm{~b} \text {. }\end{array}$ \\
\hline CD59 & $18-20$ & Igual a DAF & $\begin{array}{l}\text { Liga-se a C5b-8 e limita a li- } \\
\text { gação e polimerização de C } 9 \text {, } \\
\text { inibindo o passo final de } \\
\text { montagem do MAC na mem- } \\
\text { brana celular }\end{array}$ \\
\hline
\end{tabular}

C1-INH, inibidor de C1; CR, receptor do complemento; DAF, fator de aceleração do decaimento; MCP, proteína cofator de membrana; CD, "cluster of differentiation". Adaptado de Paul, $1999{ }^{12}$. 
etapas da ativação: (1) por moléculas as quais se ligam a fatores do complemento e então reduzem seus efeitos em componentes subsequentes da cascata, como por exemplo receptores CR1 (CD35), CR2 (CD21), CR3 (CD11b) e CR4 (CD11c/CD18); (2) por substâncias que aceleram a inativação de C3b como por exemplo fator de aceleração do decaimento (DAF) e também proteína cofator de membrana (MCP); (3) por fatores que inibem a ligação de componentes a membrana como por exemplo, proteína $S$ (vitronectina), que interage com complexos $\mathrm{C} 5 \mathrm{~b}-7 \mathrm{de}$ fase fluida levando a uma molécula solúvel em água e prevenindo a formação do MAC; (4) bloqueando a inserção de MAC na membrana celular pela ação de reguladores como protectina (CD59).

\section{3- ATEROSCLEROSE}

A aterosclerose é uma doença crônica resultante da interação complexa entre elementos do sangue, distúrbios de fluxo e anormalidade da parede dos vasos, envolvendo vários processos como inflamação, ativação endotelial, degeneração tecidual com acúmulo de lipídeos, necrose possivelmente relacionada com o efeito citotóxico de lipídeos oxidados, calcificação e trombose com recrutamento de plaquetas e formação de fibrina, etc. As lesões da aterosclerose resultam de uma série de respostas celulares e moleculares específicas que podem no seu conjunto caracterizá-la como uma doença inflamatória ${ }^{36 / 40}$. Estas lesões ocorrem principalmente em artérias musculares e elásticas de médio e grande calibre, levando a um espessamento da camada íntima devido ao acúmulo de lipídeos e tecido conectivo. As consequências da aterosclerose são isquemia do coração e cérebro, ou infarto, umas das principais causas atuais de morte no mundo.

\section{1- Fatores que promovem aterogênese}

Numerosas observações em humanos e animais levam à hipótese de que a denudação do endotélio, que consiste na sua remoção mecânica, é o primeiro passo na aterosclerose ${ }^{36}$. Mais recentemente, uma outra hipótese aponta que, mais importante que a denudação, é a disfunção endotelial sendo a atividade reduzida do óxido nítrico um dos mais importantes marcadores deste fenômeno.

Possíveis causas da disfunção endotelial levando à aterosclerose incluem elevação nos níveis de lipoproteína de baixa densidade (LDL) oxidado, radicais livres oriundos do tabagismo, hipertensão, diabe- tes mellitus, alterações genéticas, concentrações plasmáticas elevadas de homocisteína que oxidada gera radicais livres de oxigênio estimuladores da proliferação de células musculares lisas, e infecções por microrganismos $^{36 / 39,41}$. Esta disfunção endotelial leva a respostas compensatórias que alteram as propriedades homeostáticas normais do endotélio. As diferentes formas de dano aumentam a capacidade de adesão de leucócitos e plaquetas ao endotélio. Também induzem o endotélio a expressar moléculas procoagulantes ao invés de anticoagulantes, e a gerar moléculas vasoativas, citocinas e fatores de crescimento. A resposta inflamatória estimula a proliferação de células musculares lisas na área inflamada formando uma lesão intermediária.

Com relação às células inflamatórias, os granulócitos não parecem estar presentes na aterogênese, ao contrário de macrófagos e alguns subtipos de linfócitos $\mathrm{T}$ que medeiam esta resposta em todos os estágios da aterosclerose ${ }^{42,43}$. Assim, ciclos de migração e acúmulo celular, proliferação de células musculares e formação de fibrose levam ao enlargamento e à reestruturação da lesão, a qual se torna revestida por uma capa fibrosa que por sua vez "cobre" o tecido necrótico associado ao acúmulo lipídico. Nesta fase, tem-se uma lesão avançada, que pode estreitar o lúmen e alterar o fluxo sanguíneo.

\section{2- Hipercolesterolemia, lipídeos modificados e lipoproteínas}

Alguns autores sugeriram papel causal de dietas ricas em proteínas animais na aterogênese (hipótese "metabólica") ${ }^{44}$. Entretanto, outros investigadores acreditam que os lipídeos é que causariam esta doença, sendo introduzida desde então a "teoria colesterol" da aterogênese ${ }^{45}$.

A dieta aterogênica (Figura 2) leva a níveis aumentados de LDL oxidado e consequentemente a um aumento da expressão de moléculas de adesão como VCAM-1, ICAM-1, selectinas P e E, as quais promovem a adesão de monócitos e linfócitos no endotélio. Uma vez aderidos, ocorre a penetração monocitária na parede arterial pela ação de citocinas com propriedades quimioatrativas (quimiocinas) como MCP-1, CCR2, CxCR2. Em seguida, os monócitos adquirem propriedades de macrófagos teciduais e há modulação fenotípica na expressão dos receptores removedores de LDL modificado por oxidação e glicação (receptores "scavengers" SRA-1 e CD36) ${ }^{46 / 51}$. Em condições normais, o sequestro de LDL modificado constitui passo importante no papel protetor dos macrófa- 
gos na resposta inflamatória ${ }^{52,53}$, minimizando assim os efeitos de LDL sobre as células endoteliais e musculares. Assim, ocorre a internalização destas partículas de lipoproteínas pelos macrófagos transformando-os em células espumosas. Além do efeito citotóxico, LDL é quimiotático para outros monócitos, podendo então explicar a replicação dos macrófagos bem como a sua entrada na lesão. Estas células espumosas modificam o microambiente ao secretar citocinas proinflamatórias levando a um aumento da resposta infla-

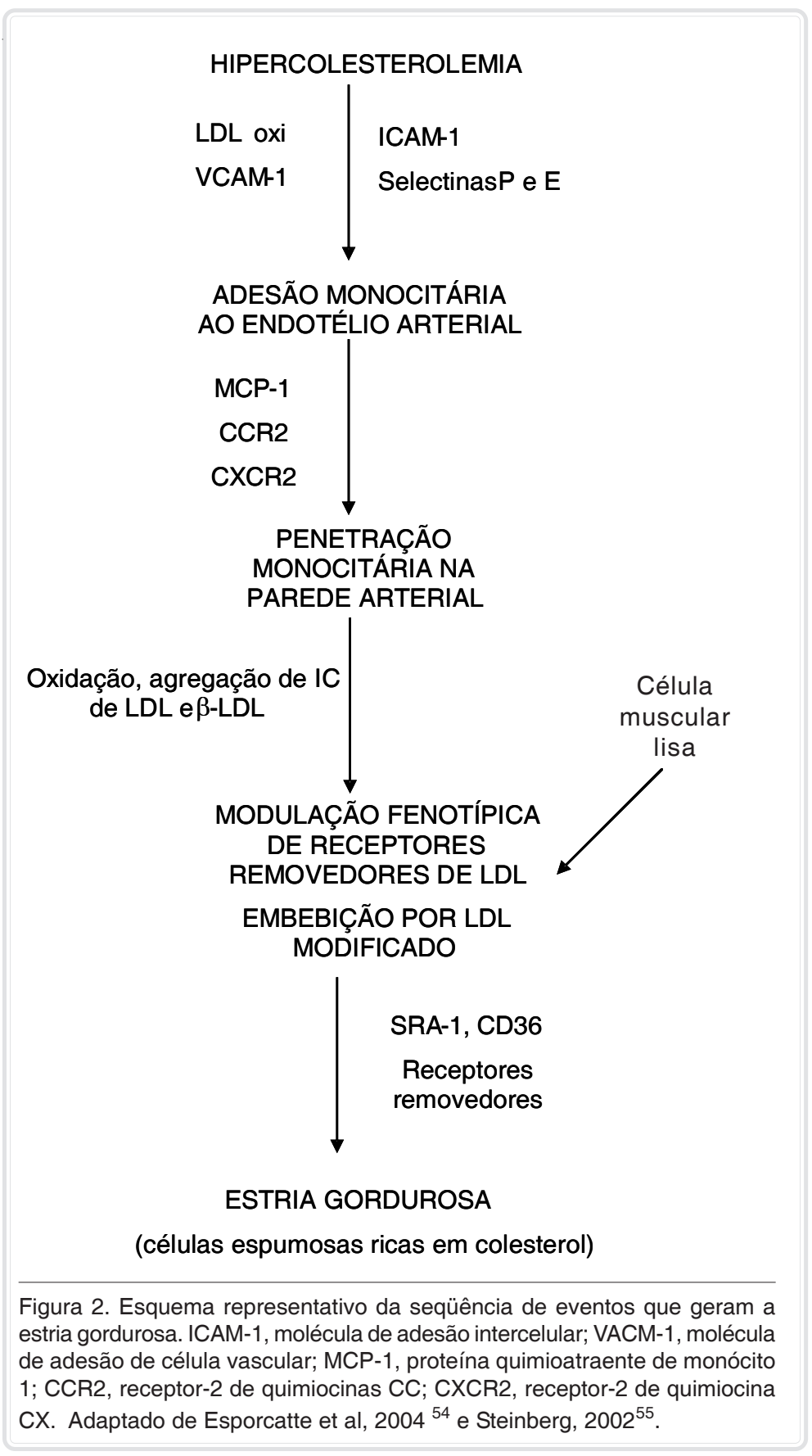

matória local, induzindo também a produção de radicais de oxigênio. Além disso, os fagócitos mononucleares estão envolvidos no processo de instabilização e trombose da placa já que a degradação da matriz se faz pelas metaloproteinases e exposição ao fator tecidual (procoagulante) produzido por estas células.

A resposta inflamatória por si só pode promover um efeito no movimento de lipoproteínas dentro da artéria, uma vez que mediadores inflamatórios, como IL-1, TNF- $\alpha$, aumentam a ligação de LDL ao endotélio e células musculares ${ }^{56}$.

LDL oxidado ocorre em lesões ateroscleróticas humanas ${ }^{57} \mathrm{e}$, em modelos animais de hipercolesterolemia, foi observado que o uso de antioxidantes pode reduzir o tamanho das lesões ${ }^{48,58-61}$.

\section{3- Imunidade inata e adaptativa na patogênese da aterosclerose}

A lesão inflamatória crônica presente no ateroma apresenta células imunes abundantes, particularmente macrófagos e células T. Esta identificação de infiltrado inflamatório/imune nestas lesões levou alguns autores a postular o envolvimento de mecanismos imunes na aterogênese ${ }^{62,63}$.

A vasculatura, como parte do sistema imune, desempenha papel importante na circulação linfocitária e atua como portal entre tecido e compartimentos sanguíneos. Células endoteliais expressam receptores de reconhecimento de padrão molecular amplo associado a patógeno denominados "Toll-Like Receptors" (TLR) os quais induzem a expressão de moléculas de adesão de leucócitos, NO sintase 2 induzível, endotelina, interleucina 1 e outras moléculas inflamatórias. Expressam ainda receptores "scavengers", que podem internalizar partículas de LDL modificadas. A ativação destas células pode recrutar leucócitos, aumentar a permeabilidade vascular, promover edema e outras características da inflamação ${ }^{64}$. As células endoteliais podem ainda ativar a imunidade adaptativa apresentando antígenos estranhos a células T específicas, expressando moléculas do complexo principal de histocompatibilidade de classe II (MHC II) ou ativando diretamente células T CD8+ ${ }^{65,66}$. 
Estudos experimentais realizados em modelos animais bem como em cultura de células demonstram que o início da aterosclerose representa uma resposta do sistema inato ao acúmulo e modificação de lipoproteína na camada íntima arterial. Várias evidências sugerem que produtos microbianos podem promover crescimento ou ativação da placa, como LPS e proteínas de choque térmico (HSPs) ${ }^{67,68}$. Há evidências de expressão de TLR em placas de ateroma sugerindo um possível mecanismo pelo qual produtos microbianos podem ativar células da placa ${ }^{69,70}$. In vitro, estudos demonstram que várias lipoproteínas modificadas e seus constituintes podem disparar a produção de mediadores da imunidade inata ${ }^{71,72}$. O SC constitui uma família adicional de proteínas efetoras envolvidas na resposta imune inata. Sua ativação pode preceder o desenvolvimento da lesão ${ }^{73}$.

Os linfócitos T participam na formação inicial do ateroma e as células presentes nas lesões tem propriedades do subtipo Th1, ou seja, secretam INF- $\gamma$, interleucina 2 , TNF- $\alpha$ e $\beta$, com propriedades proinflamatórias e aterogênicas ${ }^{74}$. Em adição a células $\mathrm{T}$ auxiliares, placas ateroscleróticas apresentam números moderados de TCD8+ bem como célula B e mastócitos ${ }^{42,75,76 .}$

\section{4- O SC NOS PROCESSOS DE ATEROGÊNESE}

\section{1- Componentes do SC no tecido vascular}

A observação de componentes do SC e suas proteínas reguladoras em lesões ateroscleróticas tem sugerido que este sistema pode estar intimamente envolvido na aterogênese. Depósitos de C5b-9 ocorrem em aortas de coelho precedendo a infiltração de monócitos e células espumosas ${ }^{73}$.

Componentes do $\mathrm{SC}$ tais como $\mathrm{C}^{6 / 8}$ e proteínas regulatórias são observados em lesões aterosclerósticas na espécie humana. Tem sido demonstrada associação dos níveis séricos elevados de $\mathrm{C} 3$ com doença arterial coronariana severa $(\mathrm{CAD})^{77}$, com risco de infarto do miocárdio ${ }^{78}$ e hipertrigliceridemia endógena ${ }^{79}$ também em humanos. Já em modelos animais, estudos demonstraram a deposição de C3 na camada íntima de vasos de coelhos tratados com dieta hipercolesterolêmica, sugerindo um papel etiológico para o complemento na aterogênese ${ }^{80}$. Buono e colaboradores mostraram que camundongos deficientes de C3 permaneceram com lesões predominantemente com lipídeos acumulados e macrófagos, e menor conteúdo de células musculares e colá- geno $^{81}$. Foi demonstrado que deficiência de C3 mas não de fator $B$ aumenta hiperlipidemia e aterosclerose em camundongos knockout apoE e LDL ${ }^{82}$.

Schmiedt et al. ${ }^{83}$ sugeriram um efeito protetor para a deficiência de C6, uma vez que não foram observadas lesões ateroscleróticas extensas em coelhos deficientes em C6 comparando-se com animais normais, sugerindo que a sequência terminal do complemento pode estar envolvida na progressão da lesão. Contrariamente, num estudo conduzido em camundongos knockout apo E, foi verificado que não houve mudanças no tamanho da lesão entre animais apo $\mathrm{E}$ /- e animais apo E -/- deficientes de C5, sugerindo que esta deficiência de C5 pode ser compensada por MCP- $1^{84}$. Estudos clínicos sugerem que deficiência hereditária de $\mathrm{C} 2$, além de fortemente associada a infecções severas e doenças reumáticas, correlacionase com doenças cardiovasculares e acidentes vásculocerebrais, fornecendo uma nova evidência entre deficiência de $\mathrm{C} 2$ e desenvolvimento de aterosclerose ${ }^{85}$.

Componentes terminais (MAC) foram encontrados em altas concentrações na camada íntima dos vasos e em placas fibrosas ${ }^{9,86}$. Estudos mostram a expressão de CR1 e CR3 principalmente em macrófagos e em proporções menores em células musculares das lesões ${ }^{87}$. Outros reguladores como DAF, proteína S e CD59 estão presentes em células musculares lisas da lesão, não ocorrendo em células do tecido normal $^{88,89,90}$.

Tem sido relatada a ativação do SC em pacientes dislipidêmicos, ocorrendo um aumento significativo de C5b-9 solúvel (mas não de CH50, C3 e C4) e sugerindo que a ativação do SC pode estar associada a várias desordens lipídicas ${ }^{91}$. De relevância neste contexto, hiperlipidemia em hamsters parece estar associada com aumento do potencial de atividade das VC/VL e VA do SC no período pré-lesão aterosclerótica $^{92}$, que, por sua vez, pode ser decorrente, pelo menos em parte, de um aumento do potencial de atividade de C2 e Fator B, respectivamente. Estes resultados sugerem que uma maior atividade potencial do SC relacionada a hiperlipidemia pode consequentemente ocasionar uma maior ativação do SC, a qual pode ser um dos fatores deflagadores do processo inflamatório existente no início da aterogênese.

\section{2- Possíveis mecanismos de ativação do SC na aterogênese $^{93}$}

\subsection{1- Ativação pela via clássica}

Anticorpos anti-epítopos de células endoteliais ${ }^{94}$ 
e outros constituintes da parede arterial, anticorpos direcionados a certos vírus ${ }^{95}$ ou deposição de IC nos vasos podem ativar a via clássica (VC) do $\mathrm{SC}^{96}$. Além disso, imunoglobulinas podem se ligar a elementos do citoesqueleto endotelial pela região Fc e não Fab, podendo ativar o $\mathrm{SC}^{6}$. Isto parece ocorrer quando a célula endotelial já apresenta algum dano, devido por exemplo a estresse hemodinâmico. Auto-anticorpos anti-lipoproteínas ${ }^{97,98}$ podem levar a outros efeitos tais como acúmulo de lipídeos por macrófagos se depositados dentro da parede vascular e em pontos de danos pré-existentes. Estes eventos poderiam ser limitados por inibidores do SC. Células endoteliais expressam $\mathrm{DAF}^{88}$ e CD5990 e parecem proteger, pelo menos em parte, tal tecido dos efeitos da ativação do SC. Já as células musculares lisas expressam constitutivamente DAF mas não CD59, proteína esta cuja expressão pode ser induzida nestas células em certas circunstâncias ${ }^{90}$.

De maneira independente de anticorpos, esta via pode ainda ser ativada por exemplo pela ligação de vírus ${ }^{95}$. Sua participação na aterogênese ainda não é evidente, tem sido sugerida uma correlação positiva entre incidência de doenças cardiovasculares e infecções virais, como por exemplo por citomegalovírus ${ }^{99}$.

\subsection{1- Via alternativa}

Com relação à via alternativa (VA), partículas de colesterol oriundas de debris de ateromas são potentes ativadores ${ }^{10}$. Estudos demonstraram que a ativação do SC foi colocalizado com o acúmulo de colesterol na parede arterial em coelhos hipercolesterolêmicos ${ }^{73}$. Partículas de LDL obtidas por tratamento enzimático foram capazes de ativar a VA; HDL e VLDL submetidas ao mesmo tratamento não produziram o mesmo efeito ${ }^{100}$. Seifert et al. ${ }^{101}$ isolaram uma fração rica em colesterol de ateromas de aortas humanas capaz de ativar a VA de maneira dose dependente. Esta fração foi denominada ativador de complemento da lesão (LCA) e consiste de partículas esféricas de lipídeos na maioria de 100-500nm, cujo componente proteico principal corresponde a albumina. In vitro, LCA, quando incubada com monócitos humanos, promoveu a formação de células espumosas.

Como já dito anteriormente, microrganismos como por exemplo Clamydia ${ }^{102}$ podem ativar esta via e novamente elevada incidência de doenças cardiovasculares tem sido relacionada com infecções prévias por Clamydia pneumoniae ${ }^{103}$.

\section{3- Efeitos da ativação do SC nos processos de aterogênese}

\subsection{1- Recrutamento celular mediado por anafi- latoxinas}

As proteínas C3 e C5 do SC, quando clivados, resultam na formação respectivamente dos peptídeos anafiláticos $\mathrm{C} 3 \mathrm{a}$ e $\mathrm{C} 5 \mathrm{a}^{28,104}$, os quais são estrutura e funcionalmente semelhantes, embora o $\mathrm{C} 5 \mathrm{a}$ apresente propriedades quimiotáticas mais potentes, elicitando o recrutamento de todas as células mielóides. Sua clivagem pelo potente inativador plasmático de anafilatoxina, a carboxipeptidase $\mathrm{N}$, gera o produto $\mathrm{C} 5$ a desArg, que ainda sustenta sua atividade quimiotática, o que não ocorre com C3a desArg, que é totalmente inativo.

Se C5b-9 está presente nas lesões arteriais, obviamente os fragmentos C3a e C5a foram gerados. No entanto, somente monócitos e linfócitos T são observados na lesão, apesar de suas propriedades quimiotáticas para neutrófilos. Provavelmente isto pode ocorrer devido a uma insuficiência da quantidade de anafilatoxina formada em recrutar neutrófilos ou C5a se torna inativo quando liga-se ao subendotélio. Outra hipótese seria o fato do padrão de molécula de adesão expressado pelo endotélio não permitiria a ligação de neutrófilos. Além disto, as células musculares lisas expressam receptores para $\mathrm{C}_{5} \mathrm{a}^{105}$, que parece ser quimioatraente para as mesmas células.

\subsection{2- Ataque inocente ("bystander"), lise poten- cial de células vasculares e "shedding" de membrana não lítico}

Com a produção de MAC, pode-se esperar que tenha efeito direto na superfície da célula ativadora. Mas também é bem provável que células vizinhas à ativadora (inocentes) possam ser afetadas por um fenômeno denominado ataque inocente ("bystander"). C5b-6, intermediário na formação do MAC, pode se difundir do sítio de ativação do SC e ligar-se a membranas celulares adjacentes. Tal fenômeno tem sido mimetizado in vitro através de um mecanismo de lise reativa ${ }^{106}$. A distância que C5b-6 deve se difundir antes de se tornar inativo pode limitar sua ocorrência. No entanto, considerando que as células de uma lesão ateroscleróticas estão muito próximas uma das outras, tal evento pode possivelmente acontecer.

Como já dito, células nucleadas parecem ser resistentes à ação lítica do MAC, provavelmente devido à expressão de proteínas regulatórias ou outros 
mecanismos defensivos como por exemplo "shedding" de membrana. Se isto realmente ocorre, para o SC promover a lise de células arteriais, seriam necessárias doses extremamente elevadas de MAC ou então, a lise ocorreria somente em células altamente susceptíveis como aquelas com distúrbios metabólicos ou senescentes.

Com relação ao "shedding" de membrana, as lesões promovidas pelo MAC parecem ser instáveis em certas células, que evitam a lise respondendo a formação do MAC pelo "shedding" de membrana. Células endoteliais apresentam um processo de protrusão da membrana, que parece ocorrer em resposta a certos estímulos tóxicos como fumaça de cigarro $^{107}$ e ao $\mathrm{MAC}^{108}$ podendo resultar na liberação de substâncias intracelulares.

Evidências mostram que doses sublíticas de MAC podem levar a respostas celulares ${ }^{109}$ na ausência de morte celular. Estudos demonstraram que MAC induz secreção de IL-8, MCP-1 ${ }^{110}$; expressão de selectina $\mathrm{P}$ e secreção de fator de von Willebrand ${ }^{111}$ bem como a expressão de moléculas de adesão (selectina E e molécula de adesão intercelular 1 (ICAM-1) ) em células endoteliais ${ }^{112}$. Produção e liberação de metabólitos do ácido aracdônico incluindo prostaglandinas e leucotrienos, reconhecidamente envolvidos na mediação da dor e inflamação, são estimuladas por quantidades não letais de $\mathrm{MAC}^{109}$. Fatores de crescimento e citocinas liberadas em resposta à concentrações sublíticas de MAC possuem implicações importantes na aterogênese. $\mathrm{O}$ fator de crescimento plaquetário (PDGF), potente mediador da proliferação de células musculares, é demonstrado em níveis elevados em lesões ateroscleróticas ${ }^{113}$. MCP1 , uma vez no interior do vaso, pode ser quimiotático para monócitos e linfócitos $\mathrm{T}^{114,115}$ mas não para neutrófilos e células $\mathrm{B}$, explicando a predominância das células monocíticas e T na lesão provavelmente devido a um gradiente apropriado promovido pela sua produção por células musculares lisas, o que é improvável de ocorrer quando liberado pelo endotélio.

Outras funções do MAC, em doses sublíticas, têm sido demonstradas como por exemplo estimulando o aumento de cálcio intracelular ${ }^{109}$ e a síntese de colágeno ${ }^{116,117}$.

\section{5- PERSPECTIVAS}

Em síntese, os dados da literatura atual sugerem que a ativação do SC está diretamente envolvida no processo inflamatório que ocorre na aterogênese, participando desde a fase de pré-lesão até a placa aterosclerótica já estabelecida. A ativação do SC e consequente formação do MAC pode levar a danos teciduais ou lise, além de, em doses sublíticas, desencadear vários outros fenômenos com ativação e proliferação celular. O peptídeo C5a e MCP-1 liberados durante a ativação deste sistema podem participar no recrutamento de monócitos nos estágios pré-lesionais da aterogênese. Considerando a reconhecida função de mediadores inflamatórios, o SC e macrófagos tem possivelmente papel importante no início e desenvolvimento da lesão.

Assim, o potencial terapêutico de inibição do SC tem sido alvo de vários estudos atuais, uma vez que este sistema participa efetivamente de várias doenças inflamatórias, como a aterosclerose, e de doenças auto-imunes. Uma idéia atrativa é bloquear a ativação de suas proteínas solúveis C3a e C5a, sendo que desativando $\mathrm{C} 3$, a via não se propagaria eficientemente até C5b-9. No entanto, devemos lembrar que tal benefício é contrabalanceado pelo aumento de ocorrência de complicações relativas ao tratamento como infecções. Outra estratégia de controle seria a produção de componentes reguladores solúveis e de membrana, através de técnicas avançadas de proteínas recombinantes, que poderiam de forma reversível dissociar C3 e C5 convertases, atuar como inibidores irreversíveis servindo de cofatores para fatores que convertem proteínas ativas em inativas (DAF, MCP) ou ainda bloquear a inserção do MAC (CD59).

Vale citar o exemplo das estatinas, amplamente utilizadas na terapia de hiperlipidemias como inibidoras da HMG-coA-redutase, e que têm revelado atividades biológicas importantes. Entre estas estão as atividades antiinflamatória e imunomodulatória, como inibição da adesão de leucócitos e extravazamento em inflamação aguda mediada pelo $\mathrm{SC}^{118}$, e expressão aumentada de DAF no endotélio vascular, protegendo-o contra o dano mediado pelo $\mathrm{SC}^{119}$, além de redução dos níveis de C3 e C4 em pacientes com doenças cardiovasculares $^{120}$.

Aplicações terapêuticas da administração intravenosa de imunoglobulinas policlonais (IVIg) normais (principalmente do isotipo IgG) têm sido investigadas no tratamento de doenças infecciosas, autoimunes e inflamatórias sistêmicas. Com relação a aterosclerose, imunomodulação pela administração de IVIg tem mostrado ser efetiva na inibição da progres- 
são da lesão, possivelmente modulando a ativação de célula $\mathrm{T}$ e/ou produção de anticorpos ${ }^{121}$. Persson et al. ${ }^{122}$ mostraram que o tratamento com IVIg reduziu a aterosclerose em camundongos deficientes de receptor para LDL e apolipoproteína E mas não nos mesmos animais porém também deficientes de C3. Esta inibição da progressão da lesão parece então ocorrer por um mecanismo via sistema complemento.
Finalmente, considerando o reconhecido envolvimento do SC na aterogênese, desde os estágios prelesionais até a progressão e estabelecimento da placa aterosclerótica, estudos futuros de inibição deste sistema tornam-se interessantes com intuito de se obter ferramentas terapêuticas para o controle e tratamento de inúmeras doenças de caráter inflamatório, como por exemplo, a aterosclerose.

Landi-Librandi AP, Assis-Pandochi Al. The involvement of the Complement System in the processes in atherogenesis. Medicina (Ribeirão Preto) 2008; 41 (3): 312-26.

ABSTRACT: Atherosclerosis has been considered a chronic inflammatory illness induced by macrophage activation, T lymphocyte and complement system. This system corresponds to a group of plasma and membrane proteins, which are activated by a cascade of interactions that result in the production of some pro-inflammatory molecules. Although it is one of the effector mechanisms of the innate immune system, in certain circumstances, the system complement can itself contribute for "triggering" cardiovascular diseases. This review contains a brief description of the complement cascade and the processes of atherogenesis as well as the involvement of immunological factors, mainly the complement system activation on patogenesis of atherosclerosis.

Keywords: Complement System Proteins. Atherosclerosis. Inflammation. Complement Membrane Attack Complex. Atherogenesis.

\section{REFERÊNCIAS}

1 - Gardinali M, Conciato L, Cafaro C, Agostino A . Complement system in coronary heart disease: a review. Immunopharmacol. 1995; 30:105-7.

2 - Smiley JD, Moore SE. Immune complex vasculitis: role of the complement and IgG Fc receptor functions. Am J Med Sci 1989; 289: 267-77.

3 - Faulk WP, Labarrere CA, Pitts D, Halbrook H. Laboratory clinical correlates of the time associated lesions in the vascular immunopathology of human cardiac allografts. J Heart Lung Transplant. 1993;12: S125-134.

4 - Ross R. Mechanisms of disease atherosclerosis an inflammatory disease. N Engl J Med 1999; 340:115-26.

5 - Geertinger P, Sorensen $\mathrm{H}$. Complement as a factor in atherosclerosis. Acta Pathol Microbiol Scand.[A] 1970;78:72933.

6 - Hansson GK, Holm J, Kral IG. Accumulation of IgG and complement factor $\mathrm{C} 3$ in human arterial endothelium and atherosclerotic lesions. Acta pathol microbiol immunol scand [A] 1984;92: 429-35.

7 - Hollander W, Colombo MA, Kramsch DM, Kirkpatrick B. Soluble proteins in the human atherosclerotic plaque. With spectral reference to immunoglobulins, C3 complement component, alpha I antitrypsin and alpha 2 macroglobulin. Atherosclerosis. 1979; 34: 391-405.

8 - Vlaicu R, Niculescu F, Rus HG, Cristea A . immunoglobulins and complement components in human aortic atherosclerotic intima. Atherosclerosis. 1985; 55:35-50.

9 - Vlaicu R, Niculescu F, Rus HG, Cristea A. Immunohistochemical localization of the terminal C5b-9 complement complex in human aortic fibrous plaque. Atherosclerosis. 1985; 57: 163-77.

10 - Seifert PS, Kazatchkine MD. The complement system in atherosclerosis. Atherosclerosis. 1988; 73:91-104.

11 - Torzewski J, Oldroyd R, Lachmann PJ, Fitzsimmons CJ, Proudfoot D, Bowyer DE. Complement induced release of monocyte chemotactic protein from human smooth muscle cells a possible initiating event in atherosclerotic lesion formation. Arterioscler Thrombos Vasc Biol. 1996; 16: 673-7.

12 - Paul EW. Complement. In: Fundamental Immunology. 4aㅡ ed. Lippincott-Raven Publishers;1999. p. 967-95.

13 - Walport MJ. Complement. First of two parts. N Engl J Med 2001; 344:1058-66.

14 - Prodinger WM, Wurzner R, Erdei A, Dierich MP. Complement. In: Paul EW . Fundamental Immunology. 4⿳亠丷厂 ed.Philadelphia: Lippincott-Raven Publishers;1999. p. 967-96. 
15 - Steel DM, Whitehead AS. The major acute phase reactants: C-reactive protein serum amyloid $\mathrm{P}$ component and serum amyloid A protein. Immunol Today. 1996;15:81-7.

16 - Weiser MR, Williams JP, Moore Jr. FD, Kobzik L, Ma M, Hetchman HB, Carroll MC. Reperfusion injury of ischemic skeletal muscle is mediated by natural antibody and complement. J Exp Med. 1996;183:2343-8.

17 - Korb LC, Ahearn JM. C1q binds directly and specifically to surface blebs of apoptotic human keratinocytes. J Immunol. $1997 ; 158: 4525-8$

18 - Morgan B.P. Physiology and pathophysiology of complement progress and trens. Science 1995: 32: 265-89.

19 - Reid KB, Turner MW. Mammalian lectins in activation and clearance mechanisms involving the complement system. Springer Semin Immunopathol. 1994; 15:307-26.

20 - Luh J, The C, Kishore U, Reid KBM. Collectins and ficolins: sugar pattern recognition molecules of the mammalian innate immune system. Biochim Biophys Acta. 2002;1572:387-400.

21 - Roos A, Bouwman LH, van Gijlswijk-Janssen DJ, Faber-Krol MC, Stahl GL, Daha MR. Human IgA activates the complement system via the mannan-binding lectin pathway. J Immunol. 2001; 167: 2861-8.

22 - Turner MW, Hamvas RM. Mannose-binding lectin: targetin the microbial world for complement attack and opsonophagocytosis. Rev Immunogenet. 2000; 2: 303-22.

23 - Hummel DS, Berninger RW, Tomasz A, Winkelstein JA. The fixation of $\mathrm{C} 3 \mathrm{~b}$ to pneumoco-ccal cell wall polymers as a result of activation of the alternative complement pathway. J Immunol. 1981; 127: 1287-9.

24 - Fearon DT, Austen KF. Properdin: Binding to C3b and stabilization of the C3b-dependent C3 conver-tase. J Exp Med. 1975;142: 856-63.

25 - Platts-Mills TAE, Ishizaka K. Activation of the alternative pathway of human complement by rabbit cells. J Immunol. 1974;113:348-58

26 - Lachmann PJ. Inherited complement deficiencies. Philos Trans R Soc Lond B Biokl Sci 1984; 6: 419-40.

27 - Esser AF. Big MAC attack: complement proteins cause leaky patches. Immunol Today. 1991; 12: 316-8.

28 - Morgan BP. Complement membrane attack on nucleated cells: resistance, recovery and non-lethal effects. Biochem J.1989; 15: $1-14$.

29 - Dameron B. Biological activities of complement-derived peptides. Rev Physiol Biochem Pharmacol. 1987;108: 151206.

30 - Davies KA, Schifferli JA, Walport MJ. Complement deficiency and immune complex disease. Springer Semin Immunopathol. 1994;15: 397-416.

31 - Taylor PR, Carugati A, Fadok VA, Cook, HT, Andrews M, Carroll MC et al. A hierarchical role for classical pathway complement proteins in the clearance of apoptotic cells in vivo. J Exp Med. 2000;192: 359-366.

32 - Schifferli JA, Taylor RP. Phisiological and pathological aspects of circulating immune complexes. Kidney int. 1989; 35: 9931003.

33 - Pascual M, Schifferli JA. Le récepteur CR1 éytrocytaire: liaison el transport des complexes immuns dans la circulation sanguine. Schweiz. Med. Wochenschr. 1993; 123:39-43.

34 - Morgan EL, Thomas ML, Hoeprich PH, Hugli TE. Bioactive complement fragments in immunoreg-ulation. Immunol Lett. 1985;134: 207-13.

35 - Shin ML, Carney .F. Cytotoxic action and other metabolic consequences of terminal complement proteins. Prog Allergy. 1988;40: 44-81.

36 - Ross R, Glomset JA. Atherosclerosis and the arterial smooth muscle cell: proliferation of smooth muscle is a key event in the genesis of the lesions of ahterosclerosis. Science 1973; 180: $1332-9$

37 - Ross R, Glomset JA . The pathogenesis of atheros-clerosis . N Engl J Med 1976;295: 369-72.

38 - Ross R. The pathogenesis of the atherosclerosis - an update. N Engl J Med 1986;314: 488-500.

39 - Ross R. The pathogenesis of atherosclerosis: a perspective for the 1990's. Nature 1993; 362: 801-9.

40 - Ross R. Atherosclerosis: a defense mechanism gone away. Am J Pathol 1993;143:987-1002.

41 - Ross R. Atherosclerosis - a problem of the biology of arterial wall cells and their interactions with blood components. Arterioscler. 1981; 1:293-311.

42 - Jonasson L, Holm J, Skalli O, Bondjers G, Hansson GK. Regionall accumulations of $T$ cells, macrophages, and smooth muscle cells in the human atherosclerotic plaques. Arterioscler. 1986;6: 131-8.

43 - Van der Wal AC, Das PK, Bentz van der Berg D, van der Loos CM, Becker A E. Atherosclerotic lesions in humans: in situ immunophenotypic analy-sis suggesting an immune mediated response. Lab Invest. 1989;61: 166-70.

44 - Ignatowski AC. Influence of animal food on the organism of rabbits. S. Peterb. Izviest. Imp. Voyenno-Med. Akad 1908;16: 154-173.

45 - Moghadasian HM. Experimental atherosclerosis. A historical overview. Life Sci. 2002;70: 855-65.

46 - Steinberg D. Low density lipoprotein oxidation and its pathobiological significance. J Biol Chem. 1997;272:20963-6.

47 - Khoo JC, Miller E, Pio E, Steinberg D, Witztum JL.. Monoclonal antibodies LDL further enhance macrophage uptake of LDL aggregates. Arterioscler Thromb. 1992;12: 258-66.

48 - Navab M, Berliner JA, Watson AD, Hama SY, Territo MC, Lusis AJ et al. The Yin and Yang of oxidation in the development of the fatty streak: a review based on the 1994 George Lyman Duff memorial lecture. Arterioscler Thrombos Vasc Biol. 1996;16:831-42.

49 - Morel DW, Hessler JR, Chisholm GM. Low density lipoprotein cytotoxicity induced by free radical peroxidation of lipid. $J$ Lipid Res. 1983;24: 1070-6. 
50 - Griendling KK, Alexander RW. Oxidative stress and cardiovascular disease. Circulation. 1997;96: 3264-5.

51 - Han J, Hajjar DP, Febbraio M, Nicholson A C. Native and modified low density lipoproteins increase the functional expression of the macrophages class B scavenger receptor, CD36. J Biol Chem. 1997; 272: 21654-9.

52 - Diaz MN, FREI B, Vita JA, Keaney JF. Antioxidants and atherosclerosis heart disease. N Engl J Med 1997;337: 40816.

53 - Falcone DJ, McCaffrey TA, Vergilio JA. Stimulation of macrophage urokinase expression by polyanions is protein C-dependent and requires protein and RNA synthesis. J Biol Chem. 1991;266: 22726-32.

54 - Esporcatte R, de Albuquerque DC, Rocha RM, Rangel FOD. Aterosclerose, inflamação e infecção. Revista da SOCERJ 2004; 17:19-25.

55 - Steinberg D. Atherogenesis in perspective: Hypercholesterolemia and inflammation as partners in crime. Nature Medicine 2002;8:1211-17

56 - Stopeck AT, Nicholson A C, Mancini FP, Hajjar DP. Cytokine regulation of low density lipoprotein receptor gene transcription in HepG2 cells. J Biol Chem. 1993;268: 17489-94.

57 - Yla-Herttuala S, Palinski W, Rosenfeld ME, Parthasarathy S, Carew TE, Butler $S$ et al. Evidence for the presence of oxidatively modified low density lipoprotein in atherosclerotic lesions of rabbit and man. J Clin Invest. 1989;84: 1086-95.

58 - Carew TE, Schwenke DC, Steinberg D. Antiatheriogenic effect of probucol unrelates to its hypocholesterolemic effect: evidence that antioxi-dants in vivo can selectively inhibit low density lipoprotein degradation in macrophagerich fatty streaks and slow the progression of atherosclerosis in the Watanabe heritable hyperlipidemis rabbits. Proc. Natl. Acad. Sci. U. S. A. 1987;84: 7725-9.

59 - Kita T, Nagano Y, Yokode M, Ishii K, Kume N, Osshima A et al.. Probucol prevents the progres-sion of atherosclerosis in Watanabe heritable hyperlipidemic rabbit, an model for familial hyper-cholesterolemia. Proc. Natl. Acad. Sci. U. S. A. 1987; 84: 5928-31.

60 - Sasahara M, Raines EW, Chait A, Carew TE, Steinberg D, Wahl PW et al. Inhibition of hypercho-lesterolemia-induced atherosclerosis in the nonhu-man primate by probucol. I. Is the extent of atheros-clerosis related to resistance of LDL to oxidation? J Clin Invest. 1994;94: 155-64.

61 - Chang MY, Sasahara M, Chait A, Raines EW, Ross R. Inhibition of the hypercholesterolemia-induces atherosclerosis in the nonhuman primate by probucol. II. Cellular composition and prolife-ration. Arterioscler Thrombos Vasc Biol. 1995;15: 1631-40.

62 - Hansson GK, Jonasson L, Seifert PS, Stemme S. Immune mechanisms in atherosclerosis. Atherosclerosis. 1989;9: 567-78.

63 - Libby P, Hansson GK. Involvement of the immune system in human atherogenesis: current knowledge and unanswered questions. Lab Invest. 1991;64: 5-15.

64 - Hansson GK, Libby P, Schonbeck U, Yan ZQ. Innate and adaptive immunity in the pathogenesis of atherosclerosis. Circ Res. 2002;91: 281-91.

65 - Pober JS, Collins T, Gimbrone MA, Libby P, Reiss CS. Inducible expression of class II major histocom-patibility complex antigens and the immunogenicity of vascular endothelium. Transplantation. 1986; 41: 141-6.

66 - Epperson DE, Pober JS. Antigen-presenting function of human endothelium cells: direct activation of resting CD8 T cells. J Immunol. 1994;153:5402-12.

67 - Libby P, Egan D, Skarlatos S. Roles of infectious agents in atherosclerosis and restenosis: an assessment of the evidence and need for future research. Circulation. 1997;96: 4095-103.

68 - Epstein SE, Zhou YF, Zhu J. Infection and atherosclerosis: emerging mechanistic paradigms. Circulation. 1999;110:208.

69 - Edfeldt K, Swedenborg J, Hansson GK, Yan ZQ. Expression of Toll-like receptors in human atheros-clerotic lesions: a possible pathway for plaque activation. Circulation. 2002;105:1158-61.

$70-\mathrm{Xu}$ XH, Shah PK, Faure E, Equils O, Thomas L, Fishbein MC et al. Toll-like receptor- 4 is expressed by macrophages in murine and human lipid-rich atherosclerotic plaques and upregulated by oxidi-zed LDL. Circulation. 2001;104: 3103-8.

71 - Witztum JL, Berliner JA. Oxidized phospholipids and isoprostanes in atherosclerosis. Curr Opin Lipidol. 1998;9: 441-8.

72 - Rajavashisth TB, Andalibi A, Territo MC, Berliner JA, Navab $M$, Fogelman, $A M$ et al. Unduction of endothelial cell expression of granulocyte and macrophage colonystimulating factors by modified low-density lipoproteins. Nature 1990;344: 254-7.

73 - Seifert PS, Hugo F, Hansson GK, Bhadki S. Prelesional complement activation in experimental atherosclerosis. Terminal C5b-9 complement deposition coincides with cholesterol accumulation in the aortic intima of hypercholesterolemic rabbits. Lab Invest. 1989;60: 747-57.

74 - Frostergard J, Ulfgren AK, Nyberg P, Hedin U, Swedenborg $J$, Aandersson $U$ et al. Cytokine expression in advanced human atherosclerotic pla-ques: dominance of proinflammatory (Th1) and macrophage-stimulating cytokines. Atherosclerosis. 1999; 145: 33-43.

75 - Zhou X, Paulsson G, Stemme S, Hansson GK. Hypercholesterolemia is associated with Th1/Th2 switch of the autoimmune response in atherosclerotic apo E-knockout mice. J Clin Invest. 1998; 101: 1717-25.

76 - Kaartinen M, Penttila A, Kovanen PT. Extracellular mast cell granules carry apolipoprotein B-100-containing lipoproteins into phagocytes in human arterial intima. Functional coupling of exocytosis and phagodytosis in neighboring cells. Arterioscler Thrombos Vasc Biol. 1995; 15:2047-54.

77 - Pang AS, Katz A, Minta JO. C3 deposition in cholesterolinduced atherosclerosis in rabbits: a possible etiologic role for complement in athero-genesis. J Immunol. 1979;123: 111722.

78 - Szeplaki G, Prohaszka Z, Duba J, Rugonfalvi-Kiss S, Karadi I, Kokai $\mathrm{M}$ et al. Association of high serum concentration of 
the third component of complement (C3) with pre-existing severe coronary artery disease and new vascular events in women. Atherosclerosis 2004;177:383-9.

79 - Muscari A, Bozzoli C, Puddu GM, Sangiorgi Z, Dormi A, Rovinetti $\mathrm{C}$ et al. Association of serum $\mathrm{C} 3$ levels with the risk of myocardial infarction. Am J Med. 1995; 98: 357-64.

80 - Uza G, Cristea A, Cucuianu MP. Increased level of the Complement C3 protein in endogenous hypertri-glyceridemia. J Clin Lab Immunol. 1982;8: 101-5.

81 - Buono C, Come CE, Witztum JL, Maguire GF, Connelly PW, Carroll $\mathrm{M}$ et al. Influence of $\mathrm{C} 3$ defi-ciency on atherosclerosis. Circulation. 2002; 105: 3025-31.

82 - Persson L, Boren J, Robertson AK, Wallenius V, Hansson GK, Pekna M. Lack of complement factor C3, but not factor $B$, increases hyperlipidemia and atherosclerosis in apolipoprotein E-/- low-density lipoprotein receptor-/- mice. Arterioscler Thrombos Vasc Biol. 2004; 24:1062-7.

83 - Schmiedt W, Kinscherf R, Geigner HP, Kamencic H, Nauen O, Kilo J et al. Complement $\mathrm{C} 6$ deficiency protects against Dietinduced Atherosclerosis in Rabbits. Atherioscler. Thromb Vasc Biol 1998; 18:1790-5.

84 - Patel S, Thelander EM, Hernandez M, Montenegro J, Hassing $\mathrm{H}$, Burton $\mathrm{C}$ et al. ApoE-/- Mice develop Atherosclerosis in the Absence of Complement Component C5. Biochem Biophys Res Commun. 2001;286:164-70.

85 - Jonsson G, Truedsson L, Sturfelt G, Oxelius VA, Braconier $\mathrm{JH}$, Sjoholm AG. Hereditary C2 deficiency in Sweden: frequent occurrence of invasive infection, atherosclerosis, and rheumatic disease. Medicine 2005;84: 23-34.

86 - Rus HG, Niculescu F, Constantinescu E, Cristea A, Vlaicu R. Immunoelectronmicroscopic locali-zation of the terminal C5b9 complement complex in human atherosclerotic fibrous plaque. Atherosclerosis. 1986;61: 35- 42.

87 - Seifert PS, Hansson GK. Complement receptors and regulatory proteins in human atherosclerotic lesions. Arterioscler. 1989;9: 802-11.

88 - Seifert PS, Hansson GK. Decay accelerating factor is expressed on vascular smooth muscle cells in human atherosclerotic lesions. J Clin Invest. 1989;84: 597-604.

89 - Niculescu F, Rus HG, Porutiu D, Ghiurca V, Vlaicu R. Immunoelectron microscopic localization of $S$ protein/ vitronectin in human atherosclerotic wall. Atherosclerosis. 1989;78: 197-203.

90 - Seifert PS, Roth I, Schmid W, Oelert H, Okada N, Okada H et al. CD59, (homologous restriction factor 20), a plasma membrane protein that protects against complement C5b-9 attack in human atherosclerotic lesions. Atherosclerosis. 1992;96: 86-93.

91 - Pasqui AL, Bova G, Puccetti L, Bruni F, Pompella G, Auteri A. Complement activation in hypercho-lesterolemia. Nutr Metab Cardiovasc Dis. 2000; 10:137-42.

92 - Landi-Librandi AP, Chrysostomo TN, Azzollini AECS, Rechia CGV, Uyemura SA, Assis-Pandochi Al. Effect of the extract of the tamarind (Tamarindus indica) fruit on the Complement System. Studies in vitro and in hamsters submitted to a cholesterol enriched diet. Food Chem Toxicol. 2007, 45: 148795.

93 - Torzewski J, Bowyer DE, Waltenberger J, Fitzsimmons C. Processes in atherogenesis: complement activation. Atherosclerosis 1997;132:131-8.

94 - Nityanand S, Bergmark C, De Faire U, Swedenborg J, Holm G, Lefvert AK. Antibodies against endothe-lial cells and cardiolipin in young patients with peripheral atherosclerotic disease. J Intern Med. 1995; 238: 437-43.

95 - Marschang P, Ebenbixhler CF, Dierich MP. HIV and complement role of the complement system in HIV infection. Int Arch Allergy Immunol. 1994; 104: 113-7.

96 - Cerilli J, Brasile L, Sosa J, Kremer J, Clarke J, Leather R et al. The role of autoantibody to vascular endothelial cells antigens in atherosclerosis and vascular disease. Transplant Proc. 1987; 19: 47-9.

97 - Bui MN, Sack MN, Moutsatsos G, Lu DY, Katz P, McCown R et al. Autoantibody titers to oxidized low density lipoprotein in patients with coronary atherosclerosis. Am Heart J.1996;131:663-7.

98 - Kacharava AG, Tertov W, Orekhov AN. Autoantibodies against low density lipoprotein and atherogenic potential of blood. Ann Med 1993;25:551-5.

99 - Melnick JL, Adam E, Debakey ME. Cytome-galovirus and atherosclerosis. Eur Heart J. 1993; 14:30-8.

100 - Bhadki S, Dorweiler B, Kirchmann R, Torzewski J, Weise $\mathrm{E}$, Tranum-Jensen $\mathrm{J}$ et al. On the patho-genesis of atherosclerosis. Enzymatic transforma-tion of human density lipoprotein to an atherogenic moiety. J Exp Med. 1995; 182: 1959-71.

101 - Seifert PS, Hugo F, Tranum-Jensen J, Zahringer U, Muhly $\mathrm{M}, \mathrm{Bhadki} \mathrm{S}$. Isolation and characte-rization of a complement activating lipid extracted from human atherosclerotic lesions. J Exp Med. 1990; 172:547-57.

102 - Hall RT, Strungnell T, Wu X, Deine DV, Sitver HG. Characterisation of kinetics and target proteins for binding of human complement component $\mathrm{C}$ to the surface-exposed outer membrane of Clamydia tra-chomatis scrovar. Infect Immunol 1993; 36:1829-34.

103 - Saikku P, Leinonen M, Tenkanen L, Linnanmaki E, Ekman MR, Manninen MM et al. Chronic Clamydia pneumoniae infection as a risk factor for coronary heart disease in the Helsinki Heart Study. Ann Intern Med. 1992;116:273-8.

104 - Gerard C, Gerard NP. C5a anaphylatoxin and its seven trasmembrane segment receptor. Ann Rev Immunol 1994; 12:775-808.

105 - Haviland DL, McCoy RL, Whitehead WT, Akama H, Molmenti EP, Brown A et al. Cellular Expression of the C5a Anaphylatoxin Receptor (C5aR): Demostration of C5aR on Nonmyeloid Cells of the Liver and Lung. J Immunol. 1995;154:1861-9.

106 - Lachmann PJ, Thompson R.A. Reactive Lysis: The complement mediated lysis of unsensitized cells. II. The characterisation of actived reactor C56 and the participation of C8 and C9. J Exp Med. 1970;71:573-86. 
107 - Pittilo RM, Bull HA, Gulati S, Rowles PM, Blow CM, Machin SJ et al. Nicotine and cigarette smoking: effects on the ultrastructure of aortic endothelium. Int J Exp Pathol. 1990; 71:573-86.

108 - Hamilton KK, Hattori R, Esmon CT, Sims PJ. Complement proteins C5b-9 induce vesiculation of the endothelial plasma membrane and expose catalytic surface for assembly of the prothrom-binase enzyme complex. J Biol Chem. 1990; 265:3809-14.

109 - Morgan BP. Effects of the membrane attack complex on nucleated cells. Curr Top Microbiol Immunol. 1992;78: 11540.

110 - Kilgore KS, Flory CM, Miller BF, Evans VM, Warren JS. The membrane attack complex of complement induces interleukin 8 and monocyte chemoattractant protein 1 secretion from human umbilical vein endothelial cells. Am J Pathol 1996; 49: 953-61.

111 - Hattori R, Hamilton KK, McEver RP, Sims PJ. Complement proteins C5b-9 induce secretion of high molecular weight multimers of endothelial von Willebrand factor and translocation of granule membrane protein GMP 140 to the cell surface. J Biol Chem. 1989; 264:9053-60.

112 - Kilgore KS, Shen JP, Miller BF, Ward PA, Warren JS. Enhancement by the complement membrane attack complex of tumor necrosis factor alpha induced endothelial cells expression of E selectin and ICAM-1. Immunology. 1995;155: 1434-41.

113 - Lindner V, Lappi DA, Baird A, Majack RA, Reidy MA. Role of basic fibroblast growth factor in vascular lesion formation. Circ Res. 1991;68: 106-13.

114 - Leonard EJ, Yoshimura T. Human monocyte chemotactic protein 1 (MCP1). Immunol Today. 1990; 11: 97-101.

115 - Oin S, Larosa G Campbell JJ, Smith-Heath H, Kassam N, Shi $\mathrm{X}$ et al. Expression of monocyte chemoattractant protein 1 and interleukin 8 receptors on subsets of T cells: correlation with transedothelial chemotatic potential. Eur J Immunol. 1996; 26: 640-7.
116 - Torbohm I, Schonermark M, Winger AM, Berger B Rohter K, Hansch GM. C5b-8 and C5b-9 mo-dulate the collagen release of human glomerular epithelial cells. Kidney Int.1990; 37:1098-104.

117 - Haensch GM, Torbohm I, Rother K. Chronic glomerulonephritis: inflammatory mediators stimulate collagen sunthesis in glomerular epithelial cells. Int Arch Allergy Appl Immunol. 1989; 88:139-43.

118 - Fischetti F, Carretta R, Borotto G, Durigutto P, Bulla R, Meroni $\mathrm{PL}$ et al. Fluvastatin treatment inhibits leucocyte adhesion and extravasation in models of complement-mediated acute inflam-mation. Clin Exp Immunol. 2004; 135: 186-93.

119 - Manson JC, Ahmed Z, Mankoff R, Lidington EA, Ahmad S, Bhatia $V$ et al. Statin-Induced Expression of DecayAccelerating Factor Protects Vascular Endothelium Against Complement-Mediated Injury. Circ Res. 2002;91: 696-703.

120 - Sampietro T, Bigazzi F, Rossi G, Dal Pino B, Puntoni MR, Sbrana $\mathrm{F}$ et al. Upregulation of the immune system in primary hypercholestero-laemia: effect of atorvastatin therapy. $J$ Inter Med. 2005;257: 523-30.

121 - Nicoletti A, Kaveri S, Caligiuri G, Baniety J, Hansson G. Immunoglobulin treatment reduces atherosclerosis in apoE knockout mice. J Clin Invest. 1998; 102:910-8.

122 - Persson L, Borén J, Nicoletti A, Hansson GA, Pekna M. Immunoglobulin treatment reduces atherosclerosis in apolipoprotein E -/- low-density lipoprotein receptor -/- mice via the complement system. Clin Exp Immunol. 2005; 142:441-5.

Recebido para publicação em 10/09/2007.

Aprovado para publicação em 26/08/2008. 